\title{
Reciprocal Relations Between Recovery and Work Engagement: The Moderating Role of Job Stressors
}

\author{
Sabine Sonnentag \\ University of Mannheim \\ Evangelia Demerouti \\ Eindhoven University of Technology
}

Eva J. Mojza

University of Konstanz

Arnold B. Bakker

Erasmus University Rotterdam

\begin{abstract}
In this paper, we examined the within-person relations between morning recovery level (i.e., feeling refreshed and replenished) and work engagement throughout the day, and between work engagement throughout the day and the subsequent recovery level at the end of the workday. We hypothesized that job stressors (situational constraints, job demands) moderate these relations. A diary study over 1 workweek with 2 measurement occasions per day ( $N=111$ persons) provided support for most of the hypotheses: Morning recovery level predicted work engagement, and work engagement predicted subsequent recovery level at the end of the workday after controlling for morning recovery level. As predicted, situational constraints attenuated these relations, but job demands did not. The results suggest that recovery translates into employee work engagement, and work engagement, in turn, prevents a loss in recovery level throughout the day, particularly when situational constraints are low. Situational constraints seem to interrupt the reciprocal processes between recovery level and work engagement.
\end{abstract}

Keywords: diary, job demands, recovery, situational constraints, work engagement

Work engagement, defined as a positive and fulfilling workrelated state of mind (Schaufeli \& Bakker, 2004), is a pleasurable experience for many workers. It goes along with feelings of energy, dedication, and absorption in one's work (Bakker, Schaufeli, Leiter, \& Taris, 2008; Schaufeli, Salanova, GonzálesRomá, \& Bakker, 2002) and is associated with good mental health and an increase in job resources over time (Schaufeli, Bakker, \& van Rhenen, 2009; Schaufeli, Taris, \& van Rhenen, 2008). Work engagement benefits the organization by stimulating task and contextual performance (Halbesleben, Harvey, \& Bolino, 2009; Salanova, Agut, \& Peiró, 2005; Sonnentag, 2003). Moreover, it is negatively related to withdrawal behavior (Newman, Joseph, \& Hulin, 2010; Schaufeli et al., 2009).

Although a person's general level of work engagement is fairly stable over time (e.g., Mauno, Kinnunen, \& Ruokolainen, 2007), a

Sabine Sonnentag, Department of Psychology, University of Mannheim, Mannheim, Germany; Eva J. Mojza, Department of Psychology, University of Konstanz, Konstanz, Germany; Evangelia Demerouti, Department of Industrial Engineering and Innovation Sciences, Eindhoven University of Technology, Eindhoven, the Netherlands; Arnold B. Bakker, Department of Work and Organizational Psychology, Erasmus University Rotterdam, Rotterdam, the Netherlands.

This research was funded by a research grant (AFF 12/00) from the University of Konstanz to Sabine Sonnentag. This grant is gratefully acknowledged. We thank Franziska Bertram and Sonja Riefer for their help during data collection.

Correspondence concerning this article should be addressed to Sabine Sonnentag, Department of Psychology, School of Social Sciences, University of Mannheim, Schloss EO 245, D-68131 Mannheim, Germany. E-mail: sonnentag@uni-mannheim.de person's day-specific level of work engagement fluctuates substantially around a person's average level of work engagement (Sonnentag, Dormann, \& Demerouti, 2010). There are days when a person who is highly engaged, on average, experiences a low level of work engagement-and also days when a generally notso-engaged person is highly engaged. These day-specific variations of work engagement within persons are not arbitrary fluctuations but can be explained by day-specific experiences and events (Bledow, Schmitt, Frese, \& Kühnel, 2011; Kühnel, Sonnentag, \& Bledow, 2012), and they predict systematic variations in outcomes, such as proactive behavior and financial returns (Sonnentag, 2003; Xanthopoulou, Bakker, Demerouti, \& Schaufeli, 2009b).

Day-specific states, such as a person's morning recovery level (i.e., the experience of being refreshed and replenished; cf. Binnewies, Sonnentag, \& Mojza, 2009), predict work engagement throughout the day (Kühnel et al., 2012). However, little is known about the affective and energetic consequences of work engagement. The question of whether work engagement is a refreshing and replenishing experience in itself-as opposed to a process that results in depletion-has been neglected so far. Our study addresses this gap in the literature. By examining both the relation between morning recovery level and work engagement throughout the day and the relation between work engagement and recovery level at the end of the workday, our study investigates the reciprocal relation between recovery level and work engagement.

Such a reciprocal relation, however, may not be present on all days. On days when employees face situational constraints (i.e., hindrance stressors that interfere with task completion), work engagement may not benefit from a high morning recovery level and may even become irrelevant for the recovery level at the end of the workday. Thus, situational constraints may attenuate the 
reciprocal relation between recovery level and work engagement. However, high job demands, which are another type of job stressor, may not have such a detrimental effect but may actually enhance the association between morning recovery level and work engagement. Our study examines situational constraints and job demands as moderators in the relation between recovery level and work engagement. We choose these stressors because they prototypically represent hindrance and challenge stressors as two core dimensions of job stressors (Podsakoff, LePine, \& LePine, 2007). Taken together, our study has two aims. First, we examine the dynamics between recovery and work engagement over the workday. Second, we examine job stressors as moderators in the relation between (a) morning recovery level and subsequent work engagement and (b) work engagement during the workday and recovery level at the end of the workday. Figure 1 shows our conceptual model.

We seek to make three contributions to the literature. First, we seek to extend previous day-level studies that have focused on performance-related outcomes of work engagement (Xanthopoulou et al., 2009b). In order to gain a better understanding of the potential consequences of work engagement, we look at recovery level as an affective and energetic state that might result from work engagement. As many employees face family responsibilities when they come home from work, it is important to know if high engagement at work results in a low recovery level after work, which would compromise effective functioning in the family (Halbesleben et al., 2009). Second, our study looks at reciprocal relations between recovery level and work engagement. It thereby adds to the growing number of studies on gain cycles and spirals associated with work engagement (Bakker \& Bal, 2010; Salanova, Llorens, \& Schaufeli, 2011) by explicitly adopting a day-level perspective. Third, by testing job stressors as moderators of the relation between recovery level and work engagement, we examine when such reciprocal processes may break down. By demonstrating that job stressors may stop reciprocial processes, our study suggests one reason why the onset of gain cycles is hindered and why - as a consequence - real gain spirals (i.e., an increase in work engagement over time) are rarely found (Salanova, Schaufeli, Xanthopoulou, \& Bakker, 2010; Xanthopoulou, Bakker, Demerouti, \& Schaufeli, 2009a). We go beyond earlier day-level research that has mainly examined job stressors as predictors of strains (Rodell \& Judge, 2009) and address the moderator effect as an additional mechanism by which job stressors affect people at work.

\section{Core Concepts}

\section{Recovery Level}

Employees' daily lives can be described as cycles of work and rest (Zijlstra \& Cropley, 2006). During work periods, employees exert effort that results in strain, while during rest periods (e.g., work breaks, free evenings) they recover from the previous strain and their physiological and psychological systems return to a more relaxed state. These cycles of work and rest imply that a person's recovery level (i.e., the person's momentary state of feeling refreshed and replenished; cf. Binnewies et al., 2009) changes during the course of the workday, with comparably high recovery levels in the morning before work and low recovery levels at the end of the workday. In addition to these within-day differences, an employee's morning recovery level might fluctuate from day to day (Sonnentag, 2003). There are days with high morning recovery levels and other days with low morning recovery levels. Similarly, the recovery level at the end of the workday should also fluctuate from day to day. Conceptually, recovery level is related to strain because both constructs reflect a person's momentary state in the cycle of work and rest (Zijlstra \& Cropley, 2006). However, recovery level and strain are distinct in that recovery level is the result of preceding leisure-time experiences and sleep, whereas strain is the result of preceding stress experiences. Empirically, recovery level and strain indicators are negatively related, but the correlations are relatively low, suggesting clearly distinct constructs (Sanz-Vergel, Demerouti, Moreno-Jiménez, \& Mayo, 2010).

\section{Work Engagement}

Schaufeli and Bakker (2004) described work engagement as "a positive, fulfilling, work-related state of mind that is characterized by vigor, dedication, and absorption" (p. 295). Vigor implies being energetic and mentally resilient at work and being willing to invest effort and to persist when difficulties arise. Dedication means being enthusiastic and inspired at work and experiencing significance, pride, and challenge. Absorption can be described as full concentration at work and as the experience of being happily engrossed in one's work. Work engagement not only differs between persons but also fluctuates within persons from day to day (Sonnentag, 2003; Xanthopoulou, Bakker, Heuven, Demerouti, \& Schaufeli, 2008). Whereas recovery level is a context-free state

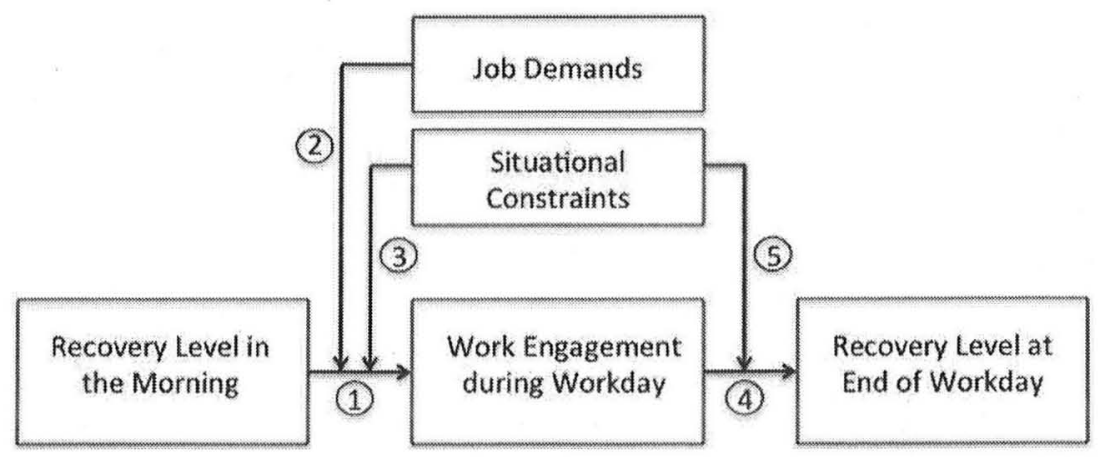

Figure 1. Conceptual model. Numbers refer to the hypotheses. 
that exists regardless of whether one is at work or not, work engagement is job related and refers specifically to the person's state while at work.

\section{Job Stressors: Job Demands and Situational Constraints}

Job demands refer to job features that ask for sustained physical or mental effort (Demerouti, Bakker, Nachreiner, \& Schaufeli, 2001). Work overload and time pressure are typical examples of job demands that are present in many jobs. Job demands are associated with short-term strain symptoms, such as affective distress, exhaustion, and fatigue (Ilies, Dimotakis, \& De Pater, 2010; Zohar, Tzischinski, \& Epstein, 2003), and longer-term health impairments (de Lange, Taris, Kompier, Houtman, \& Bongers, 2003). However, high demands are not always detrimental for job performance (LePine, Podsakoff, \& LePine, 2005) and may even stimulate work engagement (Bakker, van Emmerik, Geurts, \& Demerouti, 2008).

Situational constraints are job features that make it difficult for employees to translate their abilities and motivation into effective job performance (Peters, O’Connor, Eulberg, \& Watson, 1988). Typical situational constraints include faulty equipment, missing or inappropriate material and supplies, and missing or outdated information (Peters \& O'Connor, 1980). Situational constraints can be seen as typical hindrance stressors that make effective performance difficult or impossible (Podsakoff et al., 2007). Situational constraints have been shown to be positively related to strain symptoms (Leitner \& Resch, 2005; Spector \& Jex, 1998) and negatively related to job performance (Gilboa, Shirom, Fried, \& Cooper, 2008).

\section{Development of Hypotheses}

\section{Morning Recovery Level as Predictor of Work Engagement}

Being recovered in the morning implies feeling refreshed and having recuperated from previous strain experiences (Binnewies et al., 2009). It means being in a cognitive, emotional, and physical state that helps one to function well and to persist when difficulties occur. When one is recovered, the fatigue level is low and no other strain symptoms interfere with the work process. Such a state of being recovered enables employees to become fully immersed in their work and to fully concentrate on it. In line with a resourcebased view of work engagement and work behavior (Trougakos \& Hideg, 2009; Xanthopoulou et al., 2009b), being recovered is associated with the availability of energetic and affective resources that, in turn, facilitate work engagement. Thus, a high recovery level should be associated with a high level of work engagement. That is, if the employee arrives at work in the morning in a well-recovered state, it will be more likely for the employee to be energetic, enthusiastic, and persistent (i.e., to be highly engaged) during the workday. Earlier research identified a person's recovery level in the morning as a predictor of work engagement experienced during that day (Kühnel et al., 2012; Sonnentag, 2003). In our study, we want to replicate these findings and propose the following as our first hypothesis:
Hypothesis 1: Day-specific recovery level in the morning is positively related to day-specific work engagement during the day.

\section{Job Stressors as Moderators in the Relation Between Morning Recovery Level and Work Engagement}

We propose that the association between morning recovery level and work engagement throughout the day is not uniform across all days. Contingent on the level of job demands and situational constraints present during the day, the association between recovery level and work engagement will be stronger or weaker.

With respect to job demands, we propose that a high level of job demands enhances the association between morning recovery level and work engagement. Overall, job demands tend to be positively related to work engagement (Crawford, LePine, \& Rich, 2010). Evidence from day-level studies supports the idea of a positive association between job demands and work engagement (Bakker van Emmerik, et al., 2008; Kühnel et al., 2012), suggesting that - at least in the short run — high job demands and high work engagement are not incompatible. High job demands imply that one has a lot to do and is required to work intensely and to dedicate much effort to one's work. On days when job demands are high, one can use the energy provided by recovery to become engaged and absorbed in one's work. In other words, when faced by high demands, a high recovery level helps one to feel energetic and to dedicate oneself to one's work. On days when demands are low, however, the need for effort investment is low. On such days, a high recovery level cannot translate into work engagement because there are no demands for which the energy available could be used. As a consequence, a high recovery level will not be associated with a high level of work engagement.

Hypothesis 2: Day-specific job demands moderate the relation between day-specific recovery level in the morning and day-specific work engagement during the day. The relation will be stronger when job demands are high than when job demands are low.

We predict that situational constraints attenuate the relation between morning recovery level and work engagement throughout the day. In particular, when situational constraints are high, a high recovery level in the morning should not translate into high work engagement. There are at least two reasons for this assumed moderator effect. First, situational constraints consume the energy that has been provided by recovery. For example, when situational constraints occur (e.g., when necessary information is missing), energy has to be invested in order to overcome the constraints (e.g., searching for information), leaving less energy that can be invested into the task accomplishment process. Empirical evidence from day-level research suggests that after having encountered situational constraints at work, employees experience a reduction in vigor (Sonnentag \& Jelden, 2009). Thus, situational constraints use up the energy provided by recovery; thereby, the vigor component of work engagement is reduced. Second, situational constraints draw attention to these constraints and interrupt the work process. Thus, when one faces situational constraints, it is more difficult to become fully immersed in work processes because a part of the attentional resources is directed to the constraint and not 
to the task. Thereby, situational constraints inhibit the experience of absorption and dedication, making full work engagement unlikely. We propose that situational constraints attenuate the relation between morning recovery level and work engagement. Feeling refreshed and recovered in the morning does not result in high work engagement when situational constraints are high.

Hypothesis 3: Day-specific situational constraints moderate the relation between day-specific recovery level in the morning and day-specific work engagement during the day. The relation will be weaker when situational constraints are high than when situational constraints are low.

\section{Work Engagement as Predictor of Recovery Level at the End of the Workday}

In addition, we propose that work engagement throughout the workday is positively related to a person's recovery level at the end of the workday. Recovery level at the end of the workday reflects the amount of resources that remain after having worked the whole day. When one feels vigorous and is dedicated and absorbed in one's work, intrinsic work motivation is high (van Beek, Taris, \& Schaufeli, 2011). Intrinsic motivation implies that the main motivational force is the activity itself, which is perceived to be enjoyable and satisfying (Ryan \& Deci, 2000). In a state of high intrinsic motivation, it is easy to concentrate on the task and to show goal-directed behavior (Shirom, 2011). Thus, one can accomplish one's work without having to mobilize additional, compensatory effort or additional self-regulatory resources, which would result in fatigue later on (Hockey, 1997). In other words, when engaged at work, no- or only a few extra-resources must be mobilized to get the work done. As a consequence, resources will be maintained over the course of the workday, strain symptoms will not increase substantially, and the recovery level will stay relatively high as opposed to states of low work engagement, when strain accumulates over the course of the workday (Simbula, 2010). Day-level research on flow-an experience that is similar, although not identical to work engagement-suggests a negative association between flow and strain symptoms (Demerouti, Bakker, Sonnentag, \& Fullagar, 2012). Thus, one should still feel relatively refreshed after a high-engagement workday compared to a low-engagement workday.

Hypothesis 4: Day-specific work engagement during the day is positively related to day-specific recovery level at the end of the workday.

\section{Situational Constraints as Moderators in the Relation Between Work Engagement and Recovery Level at the End of the Workday}

The hypothesized positive association between work engagement throughout the day and recovery level at the end of the workday, however, will not occur on all days. We propose that it will be attenuated by situational constraints but not by job demands. Above, we have argued that it will be difficult to experience work engagement when facing situational constraints. However, when looking at a workday as a whole, there might be days when both work engagement and situational constraints occur. For example, one might start the day with a high level of engagement and face situational constraints later (cf. Beal, Weiss, Barros, \& MacDermid, 2005). It might also be that in rare instances, work engagement occurs despite the presence of situational constraints. In such a situation, it is necessary to deliberately ignore the constraints, if possible, in order to become absorbed in one's work. Thus, on days when situational constraints co-occur with high work engagement or follow an episode of work engagement, the benefits of work engagement for one's recovery level will be reduced. The low-strain situation enabled by a high level of work engagement will be disrupted when confronted with situational constraints that occur afterward. Moreover, attempts to ignore these constraints will be effortful and will consume energy resources. As a consequence, the low strain level cannot be preserved over the day and the recovery level will be reduced at the end of the workday.

With respect to job demands, however, we do not expect a moderator effect. Of course, job demands require that employees exert effort, which might result in a reduced recovery level. Despite this potential main effect of high job demands, job demands will not affect the hypothesized association between work engagement and recovery level. The experience of vigor will not be interrupted by high demands because the high energy level can be used directly for addressing the demands. Similarly, high demands will not interfere with dedication and absorption because the demands and the engaging experience pull the employee in the same direction that preserves energy resources. These processes imply that an employee's recovery level can still benefit from work engagement when job demands are high. Thus, we do not propose a moderator effect of job demands.

Hypothesis 5: Day-specific situational constraints moderate the relation between day-specific work engagement during the workday and recovery level at the end of the workday. The relation will be weaker when situational constraints are high than when situational constraints are low.

\section{Method}

\section{Procedure and Participants}

We recruited study participants by approaching organizations in a variety of industries (services, production, administration, banking, insurance) by phone and requesting support for our study. After managers expressed their respective organizations' willingness to participate in the study, we informed employees of these organizations via e-mail about the project and invited them to sign up individually for the study. We offered feedback about the study results after completion of data collection as an incentive for participation.

Participants were asked to complete a general survey and daily surveys implemented on handheld computers. Participants were instructed to complete the daily surveys in the morning before leaving home for work (Tuesday through Friday) and in the evening immediately after returning home from work (Monday through Friday). On average, participants completed morning surveys at 6:58 $(S D=0.58 \mathrm{hr})$ and end-of-workday surveys at 5:25 $(S D=2.02 \mathrm{hr}$ ). Participants filled in the general survey before starting with the daily surveys. They completed the daily surveys 
during a single week, albeit the specific weeks differed across participants.

The general survey was completed by 122 persons. Out of these 122 participants, 117 persons provided a total of 424 day-level morning data sets (Tuesday through Friday) and a total of 528 end-of-workday data sets (Monday through Friday). Time stamps recorded on the handheld computers indicated that 12 morning surveys and 97 end-of-workday surveys were completed at wrong times (e.g., morning surveys completed in the afternoon) and were therefore excluded from the data sets, leaving 412 valid morning data from 116 persons (on average 3.55 days per person) and 431 valid end-of-workday data from 114 persons (on average 3.78 days per person). In the next step, we matched valid morning data with valid end-of-workday data of the same day, thereby discarding 80 end-of-workday data assessed on Monday (because no morning data were assessed on Monday) and leaving 351 valid end-ofworkday data from 112 persons. Matching valid morning and end-of-workday data resulted in our final data set of 325 days nested within 111 persons.

The final sample comprised 111 persons (46.8\% women) from 30 local organizations; the number of participants per organization ranged between 1 and 17. Participants came from a broad range of occupational backgrounds, with most participants working as commercial clerks $(21.6 \%)$, employment center employees (15.3\%), engineers or information technology specialists $(14.6 \%)$, local government employees (11.7\%), bank employees (12.6\%), secretaries $(8.1 \%)$, or social workers $(5.4 \%)$. Mean age was 39.3 years $(S D=10.6)$; mean job tenure was 14.7 years $(S D=11.0)$. Most participants had flexible schedules, with an average contract work time of $38.2 \mathrm{hr}$ per week $(S D=5.1)$. Average overtime per week was $4.7 \mathrm{hr}(S D=4.5)$. About one third $(33.9 \%)$ of the participants had a leadership position. With respect to family status, $62.6 \%$ lived with a partner, $29.0 \%$ lived alone, $3.7 \%$ were single parents, and $4.7 \%$ lived with another person who was neither their partner nor their child. Among all participants, $41.4 \%$ had children $(M=$ $1.7, S D=0.7)$.

\section{Measures}

We collected data at the day and the person level. Table 1 shows the means, standard deviations, and correlations between the study variables. All items were in German. Participants provided their responses on 5-point Likert scales; the response format for all items, except state negative affect and job control, was $1=I$ fully disagree; $5=$ I fully agree.

Day-level measures. We collected day-level data in the morning (recovery level in the morning) and at the end of the workday (recovery level at the end of the workday, job demands, situational constraints, work engagement, and state negative affect).

Recovery level in the morning. We assessed participants' morning recovery levels with four items from the measure developed by Sonnentag and Kruel (2006). This measure assesses a person's momentary state of being recovered: "This morning, I feel mentally recovered," "This morning I feel physically recovered," "This morning I feel well-rested," "This morning, I am full of new energy." Cronbach's alpha computed separately for the 4 days of data collection ranged between .89 and $.91(M=.90)$.

Recovery level at the end of the workday. For measuring recovery level at the end of the workday, we used the same items as in the morning, yet this time with reference to the end of the workday (e.g., "Now, at the end of the workday, I feel mentally recovered"). Cronbach's alpha ranged between .83 and $.92(M=$ $.88)$.

Job demands. For measuring day-level job demands, we used three items from a scale developed by (Semmer, 1984; Zapf, 1993) that focused on quantitative demands. We adjusted the items for day-level measurement. A sample item is "Today I was required to work fast." Cronbach's alpha ranged between .87 and .91 $(M=.88)$.

Situational constraints. We measured day-level situational constraints with four items from the measure developed by (Semmer, 1984; Zapf, 1993). Again, we rephrased the items slightly so that they captured the day-specific level of situational constrains. A sample item is "Today I had to work with materials and information that were incomplete and outdated." Cronbach's alpha ranged between .83 and $.89(M=.87)$.

Work engagement. We assessed day-level work engagement with the nine-item version of the Utrecht Work Engagement Scale (UWES; Schaufeli, Bakker, \& Salanova, 2006) adapted for daylevel assessment. Sample items are "During my work, I felt strong

Table 1

Means, Standard Deviations, and Zero-Order Correlations of All Study Variables

\begin{tabular}{|c|c|c|c|c|c|c|c|c|c|c|c|c|c|}
\hline Variable & $M^{\mathrm{a}}$ & $S D^{a}$ & $M^{\mathrm{b}}$ & $S D^{\mathrm{b}}$ & 1 & 2 & 3 & 4 & 5 & 6 & 7 & 8 & 9 \\
\hline 1. Job control & 3.65 & 0.71 & & & - & & & & & & & & \\
\hline 2. General level of recovery & 2.30 & 0.75 & & & .18 & - & & & & & & & \\
\hline 3. General level of work engagement & 3.7 & 0.97 & & & .3 & .16 & - & & & & & & \\
\hline 4. Recovery level in the morning & 3.45 & 0.66 & 3.47 & 0.80 & .25 & .16 & .37 & - & .28 & -.03 & -.11 & .18 & -.19 \\
\hline 5. D & 3.2 & 0.66 & 3.25 & 0.70 & 3 & .15 & 5 & 4 & - & -.05 & -.24 & .46 & -.22 \\
\hline 6. D & 2.67 & 0.99 & 2.62 & 1.12 & -.02 & .03 & -.02 & -.15 & -.02 & - & .40 & -.18 & .22 \\
\hline 7. Day-level situa & 1.77 & 0.81 & 1.79 & 0.91 & -.17 & -.06 & -.09 & -.17 & -.24 & .43 & - & -.28 & .43 \\
\hline 8. Recc & 2.51 & 0.72 & 2.52 & 0.8 & .28 & .36 & .26 & .27 & .56 & -.21 & -.26 & - & -.25 \\
\hline 9. Negative affect at the end of workday & 1.30 & 0.34 & 1.31 & 0.42 & -.10 & -.03 & -.05 & -.34 & -.16 & .25 & .48 & -.18 & 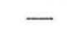 \\
\hline
\end{tabular}

Note. Correlations below the diagonal are person-level correlations $(N=111)$. Correlations above the diagonal are day-level correlations $(n=325)$. Person-level correlations of $r \geq .24$ are significant with $p<.01$, and those of $r \geq .19$ are significant with $p<.05$. Day-level correlations of $r \geq .11$ are significant with $p<.01$, and those of $r \geq .13$ are significant with $p<.05$.

${ }^{2}$ Means and standard deviations at the person level. "Means and standard deviations at the day level. 
and vigorous today," "Today, I was enthusiastic about my job," "Today, when I was working, I forgot everything else around me." Cronbach's alpha ranged between .87 and $.91(M=.90)$.

State negative affect. We used state negative affect at the end of the workday as a control variable when predicting the recovery level at the end of the workday. We included this control variable because the predictor and the outcome variable were assessed at the same point in time, and we wanted to rule out that significant associations between these two variables could be attributed to the specific measurement occasion. Participants responded to negative-affect items from the Positive and Negative Affect Schedule (Watson, Clark, \& Tellegen, 1988) on a 5-point Likert scale ranging from $1=$ not at all to $5=$ very much. To limit the time needed to complete the day-level measure, we used six items (Distressed, Upset, Irritable, Nervous, Jittery, and Afraid) as done in earlier research (Sonnentag, Binnewies, \& Mojza, 2008). Cronbach's alpha ranged between .60 and $.79(M=.69)$.

Construct validity. To examine whether the five variables assessed at the end of the workday (i.e., work engagement, recovery at the end of the workday, situational constraints, job demands, and negative affect) constitute distinct constructs, we conducted a set of multilevel confirmatory factor analyses using Mplus 6.1. A five-factor model with all items loading on their respective factors yielded an acceptable fit $\left(\chi^{2}=546.385 ; d f=289 ; p<.001\right.$; comparative fit index $[\mathrm{CFI}]=0.92$; root-mean-square error of approximation $[\mathrm{RMSEA}]=0.052$ ), and all factor loadings were significant except for one negative-affect item (Afraid) that had a marginally significant factor loading $(p=.064){ }^{1}$ All standardized factor loadings were above .40 except for three items that assessed state negative affect. This five-factor model fit the data better than the best fitting four-factor model, with situational constraints and negative affect loading on one factor $\left(\chi^{2}=719.133 ; d f=293 ; p<\right.$ .001; CFI $=0.87$; RMSEA $=0.069$; Satorra-Bentler scaled $\chi^{2}$ $\left.\left[\mathrm{S}-\mathrm{B} \chi^{2}\right]=83.8823 ; d f=4 ; p<.001\right)$; the best fitting three-factor model $\left(\chi^{2}=1123.484 ; d f=296\right.$; CFI $=0.747$; RMSEA $=0.093$, $\left.\mathrm{S}-\mathrm{B} \chi^{2}=446.2800 ; d f=7 ; p<.001\right)$; the best fitting two-factor model $\left(\chi^{2}=1556.545 ; d f=298 ; \mathrm{CFI}=0.399 ;\right.$ RMSEA $=0.142$, $\left.\mathrm{S}-\mathrm{B} \chi^{2}=621.0137 ; d f=9 ; p<.001\right)$; and a one-factor model $\left(\chi^{2}=2266.581 ; d f=299 ; \mathrm{CFI}=0.399 ;\right.$ RMSEA $\left.=0.142\right) ; \mathrm{S}-\mathrm{B}$ $\chi^{2}=1,288.64 ; d f=10 ; p<.001$ ). Thus, the five end-of-workday variables clearly represent distinct constructs.

Moreover, to establish that the recovery items (including the item "I am full of new energy") did not incidentally measure work engagement, we conducted an exploratory factor analysis of recovery and engagement items using the two-level option in Mplus. This analysis (conducted separately for recovery data assessed in the morning and recovery data assessed at the end of the workday) showed a two-factor solution in which the four recovery items had an average loading of .83 (morning) and .80 (end of workday) onto the recovery factor, and a maximum cross-loading onto the work engagement factor of .12 (morning) and .15 (end of workday).

Person-level measures. At the person level, we assessed a person's general level of recovery and general level of work engagement. For assessing the general level of recovery, we used the four-item scale developed by Sonnentag and Kruel (2006; sample item: "During my free time, I feel mentally recovered"). Cronbach's alpha was .86. We measured general level of work engagement with the nine-item version of the UWES (Schaufeli et al., 2006). Cronbach's alpha was .91. We included these variables as control variables in order to take person-level differences into account when predicting day-specific work engagement and the day-specific recovery level at the end of the workday. Because work engagement and level of recovery may depend on job control experienced (Bakker \& Demerouti, 2007; van Veldhoven \& Sluiter, 2009), we also controlled for job control. We used five items from the scale developed by (Semmer, 1984; Zapf, 1993), to be answered on a 5 -point Likert scale $(1=$ very little; $5=$ to a high degree). A sample item is "Can you influence the way in which you accomplish your tasks?" Cronbach's alpha was .78.

\section{Results}

Our data set comprised data at the person level (e.g., personlevel control variables) and at the day level (e.g., day-specific work engagement), with day-level data nested within persons. To take the noninterdependence of these data into account, we used hierarchical linear modeling to analyze the data.

\section{Descriptive Analysis}

Before testing our hypotheses, we examined within- and between-person variation in our two outcome variables (work engagement and recovery level at the end of the workday). As can be seen in the null model for work engagement (see Table 2), within-person variance (Level 1 variance) was 0.164 and betweenperson variance (Level 2 variance) was 0.345 , resulting in a total variance of 0.509 . Thus, for work engagement, within-person variance was $32.2 \%$ and between-person variance was $67.8 \%$. For recovery level at the end of the workday (see Table 3), withinperson variance was 0.383 and between-person variance was 0.360 , corresponding to $51.5 \%$ and $48.5 \%$, respectively.

\section{Test of Hypotheses}

To test our hypotheses, we compared several nested models. The null model included only the intercept. In Model 1, we included control variables; in Model 2, we entered the main effects; and in Model 3, we included the interaction effects. We tested the improvement of each model over the previous one by using the difference between the respective likelihoods. This difference follows a chi-square distribution, with the degrees of freedom corresponding to the number of parameters added to the model.

Hypotheses 1 to 3 proposed that morning recovery level will predict work engagement and that day-specific job demands and day-specific situational constraints will moderate the relation between morning recovery level and work engagement. Table 2 shows the results from hierarchical linear models predicting dayspecific work engagement from morning recovery level, job stressors (job demands, situational constraints), and the interaction terms between recovery level and job stressors (job demands, situational constraints). Model 1-including job control and general level of work engagement as control variables-showed a better model fit than the null model. A person's general level of work engagement was a highly significant predictor of day-

\footnotetext{
' We repeated all analyses, including the hypotheses tests, with a fiveitem measure of negative affect. All results remained unchanged.
} 
Table 2

Multilevel Estimates for Models Predicting Day-Specific Work Engagement

\begin{tabular}{|c|c|c|c|c|c|c|c|c|c|c|c|c|}
\hline \multirow[b]{2}{*}{ Parameter } & \multicolumn{3}{|c|}{ Null model } & \multicolumn{3}{|c|}{ Model 1} & \multicolumn{3}{|c|}{ Model 2} & \multicolumn{3}{|c|}{ Model 3} \\
\hline & Estimate & $S E$ & $t$ & Estimate & $S E$ & $t$ & Estimate & $S E$ & $t$ & Estimate & $S E$ & $t$ \\
\hline Intercept & 3.241 & 0.061 & 52.13 & 3.246 & 0.051 & 62.65 & 3.240 & 0.051 & 63.53 & 3.237 & 0.051 & 63.47 \\
\hline Job control & & & & 0.089 & 0.079 & 1.13 & 0.085 & 0.079 & 1.08 & 0.082 & 0.079 & 1.04 \\
\hline General level of work engagement & & & & 0.343 & 0.057 & $6.02^{* * *}$ & 0.343 & 0.057 & $6.02^{* *}$ & 0.338 & 0.057 & $5.93^{* *}$ \\
\hline Recovery level in the morning (REC) & & & & & & & 0.091 & 0.042 & $2.17^{*}$ & 0.062 & 0.042 & 1.48 \\
\hline Job demands (JD) & & & & & & & 0.090 & 0.038 & $2.37^{*}$ & 0.107 & 0.038 & $2.82^{* * *}$ \\
\hline Situational constraints (SC) & & & & & & & -0.161 & 0.063 & $-2.56^{*}$ & -0.155 & 0.062 & $-2.50^{*}$ \\
\hline $\mathrm{REC} \times \mathrm{JD}$ & & & & & & & & & & -0.089 & 0.073 & -1.22 \\
\hline $\mathrm{REC} \times \mathrm{SC}$ & & & & & & & & & & -0.324 & 0.156 & $-2.08^{*}$ \\
\hline$-2^{*} \log (\mathrm{lh})$ & \multirow{3}{*}{\multicolumn{3}{|c|}{547.899}} & \multirow{2}{*}{\multicolumn{3}{|c|}{$\begin{array}{c}506.409 \\
41.100^{* * * *}\end{array}$}} & \multicolumn{3}{|c|}{492.136} & \multicolumn{3}{|c|}{484.170} \\
\hline Diff $-2^{*} \log$ & & & & & & & \multirow{2}{*}{\multicolumn{3}{|c|}{$\begin{array}{l}14.275 \\
3\end{array}$}} & \multirow{2}{*}{\multicolumn{3}{|c|}{$\begin{array}{l}7.966^{*} \\
2\end{array}$}} \\
\hline$d f$ & & & & \multicolumn{3}{|c|}{2} & & & & & & \\
\hline Level 1 intercept variance $(S E)$ & \multirow{2}{*}{\multicolumn{3}{|c|}{$0.164(0.016)$}} & \multicolumn{3}{|c|}{$0.164(0.016)$} & \multicolumn{3}{|c|}{$0.153(0.015)$} & \multicolumn{3}{|c|}{$0.147(0.014)$} \\
\hline Level 2 intercept variance $(S E)$ & & \multicolumn{2}{|c|}{$0.345(0.055)$} & \multicolumn{3}{|c|}{$0.222(0.038)$} & \multicolumn{3}{|c|}{$0.224(0.038)$} & \multicolumn{3}{|c|}{$0.229(0.039)$} \\
\hline
\end{tabular}

Note. Job control and general level of work engagement are person-level (Level 2) variables; all other predictor variables are day-level (Level 1) variables. ${ }^{*} p<.05$. ${ }^{* * *} p<.01$.

specific work engagement. Model 2-including the main effectsshowed a further improvement over Model 1, with all three predictor variables being significant. Morning recovery level and job demands were positively related and situational constraints were negatively related to work engagement. Model 3-including the interaction terms-fit the data significantly better than Model 2. The interaction term between morning recovery level and situational constraints was significant. ${ }^{2}$ To gain more insight into the pattern of this interaction, we performed simple slope tests (Preacher, Curran, \& Bauer, 2006). As Figure 2 illustrates, on days with high levels of situational constraints (one $S D$ above the mean), morning recovery level was not related to work engagement; $(\gamma=-0.062 ; S E=0.079 ; z=-0.782 ; n s)$, but on days with low levels of situational constraints (one $S D$ below the mean), morning recovery level was positively related to work engagement $(\gamma=0.184 ; S E=0.066 ; z=2.811 ; p<.01)$. The interaction term between morning recovery and job demands, however, was not significant. Taken together, our data provided support for Hypotheses 1 and 3 but not for Hypothesis 2 .

Hypotheses 4 and 5 referred to the prediction of recovery level at the end of the workday. We hypothesized that work engagement during the day will be positively related to the recovery level at the end of the workday (Hypothesis 4) and that situational constraints will moderate the relation between work engagement and recovery level at the end of the workday (Hypothesis 5). In these analyses, we controlled for job control, general level of recovery, morning recovery level, and negative affect at the end of the workday because all these variables may have an impact on recovery level at the end of the workday. When testing the interaction effect between work engagement and situational constraints, we pursued a conservative strategy and also included the interaction effect between work engagement and job demands.

Table 3 shows the results. Model 1 -including the control variables-showed a better model fit than the null model. Job control and general level of recovery were positively related to recovery level at the end of the workday. Negative affect at the end of the workday showed a strong negative association with recovery level at the end of the workday. ${ }^{3}$ When we entered work engagement, job demands, and situational constraints into Model 2, model fit further improved. Work engagement was positively related to recovery level at the end of the workday, providing support for Hypothesis 4. Neither job demands nor situational constraints were significantly related to recovery level at the end of the workday. Model 3-including the interaction effects-had a better model fit than Model 2. The estimate of the interaction between work engagement and situational constraints was significant. ${ }^{4}$ Simple slope tests (Preacher et al., 2006) showed that on days when situational constraints were low (one $S D$ below the mean), work engagement during the workday had a strong positive association with the recovery level at the end of the workday $(\gamma=0.542 ; S E=$ $0.125 ; z=4.335 ; p<.001)$. On days with a high level of situational constraints (one $S D$ above the mean), work engagement was not related to the recovery level at the end of the workday $(\gamma=0.140 ; S E=0.142 ; z=0.992, n s ;$ cf. Figure 3). Overall, these findings support Hypothesis 5.

\section{Discussion}

Our study showed that morning recovery level predicted work engagement during the workday and that work engagement, in

\footnotetext{
${ }^{2}$ When only the interaction term between morning recovery level and situational constraints were entered in Model 3, the results remained very similar and the interaction term was significant $(\gamma=-0.383, S E=0.149$, $t=-2.570, p<.05$ )

${ }^{3}$ Scholars do not agree whether one should control for negative affect (Spector, 2006). Therefore, we also ran the models predicting recovery level at the end of the workday without controlling for state negative affect. The results remained unchanged. Similarly, when omitting job control from the control variables, our results did not change. Tables are available from the first author upon request.

${ }^{4}$ When only the interaction term between work engagement and situational constraints was entered in Model 3, the results did not change $(\gamma=$ $-0.465, S E=0.194, t=-3.212, p<.01$, for the interaction term).
} 
Table 3

Multilevel Estimates for Models Predicting Day-Specific Recovery Level at End of Workday

\begin{tabular}{|c|c|c|c|c|c|c|c|c|c|c|c|c|}
\hline \multirow{2}{*}{ Parameter } & \multicolumn{3}{|c|}{ Null model } & \multicolumn{3}{|c|}{ Model 1} & \multicolumn{3}{|c|}{ Model 2} & \multicolumn{3}{|c|}{ Model 3} \\
\hline & Estimate & $S E$ & $t$ & Estimate & $S E$ & $t$ & Estimate & $S E$ & $t$ & Estimate & $S E$ & $t$ \\
\hline Intercept & 2.517 & 0.068 & 37.01 & 2.507 & 0.061 & 41.10 & 2.499 & 0.061 & 40.97 & 2.486 & 0.061 & 40.75 \\
\hline Job control & & & & 0.196 & 0.091 & $2.15^{*}$ & 0.185 & 0.090 & $2.06^{*}$ & 0.189 & 0.090 & $2.10^{*}$ \\
\hline General level of recovery & & & & 0.307 & 0.086 & $3.57^{* * *}$ & 0.308 & 0.085 & $3.62^{* * *}$ & 0.301 & 0.084 & $3.58^{* * *}$ \\
\hline Recovery level in the morning & & & & 0.145 & 0.062 & $2.34^{*}$ & 0.109 & 0.061 & 1.79 & 0.095 & 0.061 & 1.56 \\
\hline Negative affect at end of workday & & & & -0.565 & 0.130 & $-4.35^{* * *}$ & -0.403 & 0.135 & $-2.99^{* * *}$ & -0.424 & 0.135 & $-3.14^{* * *}$ \\
\hline Work engagement (WE) & & & & & & & 0.359 & 0.102 & $3.52^{* * *}$ & 0.341 & 0.103 & $3.31^{* \cdot * *}$ \\
\hline Job demands (JD) & & & & & & & -0.064 & 0.057 & -1.12 & -0.050 & 0.057 & -0.88 \\
\hline Situational constraints (SC) & & & & & & & -0.029 & 0.095 & -0.30 & -0.100 & 0.098 & -1.02 \\
\hline WE $\times$ JD & & & & & & & & & & 0.089 & 0.155 & 0.57 \\
\hline $\mathrm{WE} \times \mathrm{SC}$ & & & & & & & & & & -0.525 & 0.222 & $-2.39^{*}$ \\
\hline$-2^{*} \log (\mathrm{lh})$ & \multicolumn{3}{|c|}{752.949} & \multicolumn{3}{|c|}{710.977} & \multicolumn{3}{|c|}{697.919} & \multicolumn{3}{|c|}{691.891} \\
\hline Diff $-2 * \log$ & & & & \multirow{2}{*}{\multicolumn{3}{|c|}{$41.972^{* * *}$}} & \multirow{2}{*}{\multicolumn{3}{|c|}{$13.058^{* *}$}} & \multicolumn{3}{|c|}{$6.028^{*}$} \\
\hline$d f$ & & & & & & & & & & \multicolumn{3}{|c|}{2} \\
\hline Level 1 intercept variance $(S E)$ & \multicolumn{3}{|c|}{$0.383(0.037)$} & \multicolumn{3}{|c|}{$0.347(0.033)$} & \multicolumn{3}{|c|}{$0.329(0.032)$} & \multicolumn{3}{|c|}{$0.323(0.031)$} \\
\hline Level 2 intercept variance $(S E)$ & \multicolumn{3}{|c|}{$0.360(0.069)$} & \multicolumn{3}{|c|}{$0.287(0.057)$} & \multicolumn{3}{|c|}{$0.287(0.056)$} & \multicolumn{3}{|c|}{$0.282(0.055)$} \\
\hline
\end{tabular}

Note. Job control and general level of recovery are person-level (Level 2) variables; all other predictor variables are day-level (Level 1) variables. ${ }^{*} p<.05 .{ }^{* * *} p<.01$.

turn, predicted recovery level at the end of the workday. These reciprocal relations between recovery level and work engagement did not occur under all circumstances. Situational constraints attenuated the association between morning recovery level and work engagement during the day and between work engagement during the day and subsequent recovery level. Although our data cannot demonstrate causality in a strict sense, the pattern of findings might imply that recovery level and work engagement mutually reinforce each other: The more recovered an employee is in the morning, the more engagement the employee will experience at work, which limits the decrease in the employee's recovery level over the course of the day. Situational constraints interrupt these

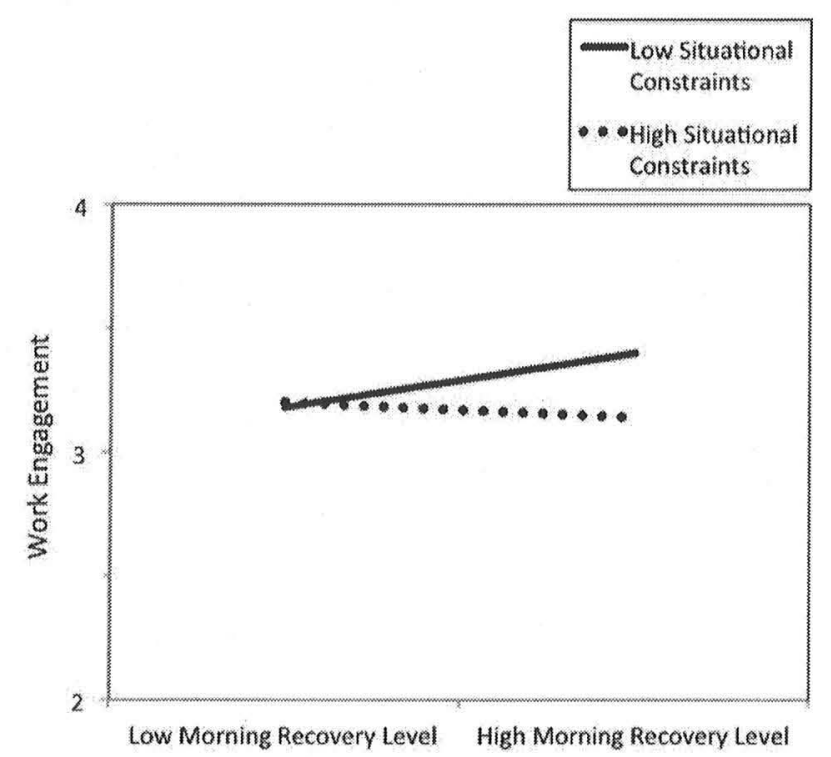

Figure 2. Prediction of work engagement. reciprocal processes between recovery level and work engagement.

Our findings, focusing on within-person fluctuations of recovery level and work engagement, extend results from studies conducted at the between-person level. These studies have identified reciprocal associations between resources, such as optimism and pride in one's profession on the one hand and work engagement on the other hand (Hakanen, Perhoniemi, \& Toppinen-Tammer, 2008; Xanthopoulou et al., 2009a). Thus, when recovery level is conceptualized as a resource (Binnewies et al., 2009), our findings point in a similar direction: Resources, including recovery level, facilitate work engagement,

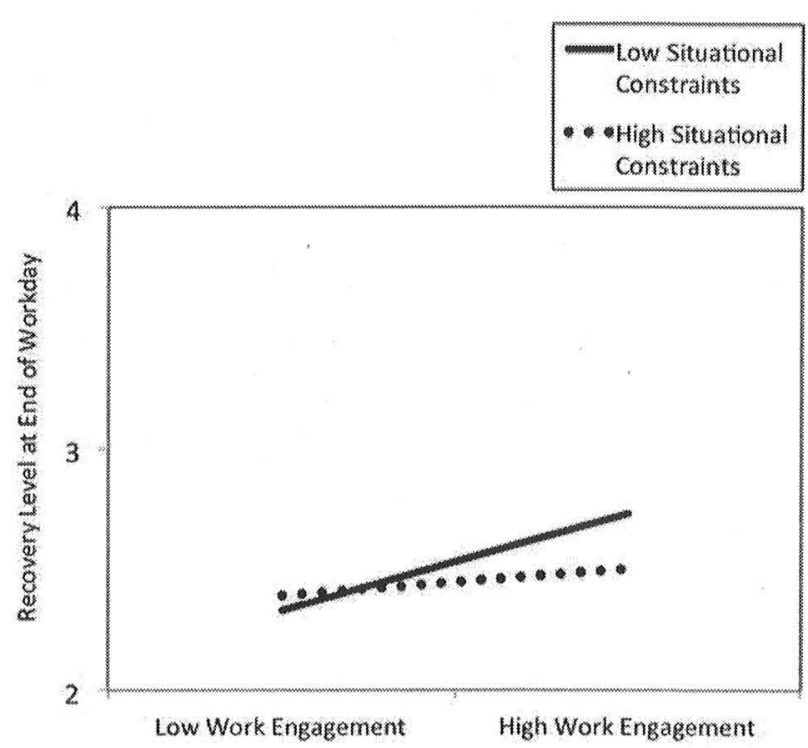

Figure 3. Prediction of recovery level at the end of the workday. 
which in turn helps to keep resources at a higher level than when work engagement is low. We have to note that in absolute terms, recovery level goes down during the course of the workday. However, one might speculate that over a series of days with high levels of morning recovery and high levels of work engagement during the day, gain cycles might occur that are reflected in increasing recovery levels and increasing levels of work engagement over the course of several days.

We identified situational constraints as harmful moderators in the recovery-engagement process. On days when situational constraints were high, the reciprocal positive associations between recovery level and work engagement broke down. One can think of at least two underlying mechanisms that render situational constraints detrimental: The first mechanism refers to the affective consequences of situational constraints. Situational constraints evoke negative affective states, such as anger and anxiety (Rodell \& Judge, 2009), that call for emotion regulation. Emotion regulation may interfere with work engagement and will consume additional resources so that the recovery level will drop. This mechanism should also apply to job demands; however, no moderator effects were found for job demands. ${ }^{5}$ Thus, a second mechanism seems more likely: Situational constraints, such as lack of information or supplies, actually impede the task completion process, requiring additional effort to get the work done. As a consequence, when one encounters situational constraints, it is more difficult to become or stay engaged (i.e., energetic, absorbed) and to keep one's recovery level.

Importantly, job demands did not turn out as a moderator, neither in the association between morning recovery level and work engagement nor in that between work engagement and recovery level at the end of the workday. Although we did not propose an interaction effect for the latter association (i.e., between work engagement and recovery level at the end of the workday), not finding an interaction effect for the first association (between morning recovery level and work engagement) was unexpected. It has to be noted that job demands did have a main positive effect on work engagement, implying that job demands and recovery level had an additive, but not a multiplicative, effect on work engagement.

One reason why the interaction between morning recovery level and job demands was not significant may be the fact that the absolute level of job demands was not very high in the present sample $(M=2.67$ on a 5-point scale). Even on days when employees did not feel so recovered, an increase in job demands might still have fueled their engagement. It is conceivable that the interaction would have been found if the average level of job demands was higher, because on very demanding days (as compared to not-so-demanding days) employees would profit more from their morning recovery level.

We found a negative relation between situational constraints and work engagement and a positive relation between job demands and work engagement. These within-person results reflect findings from a meta-analysis by Crawford et al. (2010) that used betweenperson correlations to analyze the association between various types of job stressors and work engagement. Our job demand measure largely overlaps with Crawford et al.'s notion of challenge demands (e.g., high workload), and our situational constraint measure captures core aspects of hindrance demands. In combination with the results of our moderator analyses, the overall pattern of findings suggests that these types of job stressors have rather distinct implications for work engagement. Whereas challenging demands tend to stimulate work engagement, hindrances and constraints make work engagement rather unlikely.

Recently, researchers initiated a debate on whether there is a dark side to being too engaged (Bakker, Albrecht, \& Leiter, 2011; Halbesleben et al., 2009). Hablesleben et al. found that employees with high levels of work engagement reported that work was interfering with their family life. Our study did not directly assess work-family conflict or a related construct. Our data, however, showed that at least at the day level, work engagement did not put employees in a poor affective or energetic state that might interfere with their family or other nonwork responsibilities. Rather, our data suggest that after a highly engaged day at work, employees leave the workplace in a more recovered state than that experienced on a day with less work engagement. This state should enable them to engage in nonwork activities (cf. Rothbard, 2001), again relatively more than on days with low levels of work engagement. In a broader context, our findings are compatible with a work-family enrichment perspective (Greenhaus \& Powell, 2006). Experiencing a positive state at work (e.g., work engagement) fosters positive states at the end of the workday that, in turn, will have a positive impact on nonwork life.

\section{Limitations and Directions for Future Research}

Our study is subject to several limitations that suggest directions for future research. First, we assessed our data with self-report measures, which might lead to concerns about common method variance (Podsakoff, MacKenzie, Lee, \& Podsakoff, 2003). However, because we focused on within-person fluctuations, results cannot be explained by individual differences. Moreover, for some part of the analyses we assessed predictor and outcome variables at different points in time, further reducing the likelihood that our findings are due to common method bias. Because we assessed work engagement as a predictor and recovery at the end of the workday at the same point in time, we controlled for concurrent negative affect in order to rule out that the momentary affect drove the significant relation between work engagement and recovery level. To overcome problems potentially associated with selfreport measures, future studies might assess job stressors by coworker reports or use more objective indicators of job demands and constraints (e.g., number of interruptions by phone calls).

Second, although we had two measurement occasions per day, our correlational design does not allow any conclusions about causality in a strict sense. For instance, the association between work engagement and recovery level at the end of the workday might reflect a common cause, such as positive events at work. Although we cannot rule out this possibility completely, our analysis demonstrated that work engagement predicted end-ofworkday recovery level even when morning recovery level, job

\footnotetext{
${ }^{5}$ Following the suggestion of an anonymous review, we tested whether negative affect mediated (a) the interaction effect between morning recovery level and situational constraints on work engagement and (b) the interaction effect between work engagement and situational constraints on recovery level at the end of the workday. In both analyses, we found no evidence of mediated moderation. Thus, our empirical data did not support the negative-affect mechanism.
} 
stressors, and state negative affect were included in the regression equation. Future studies might control for positive events encountered during the day and realize a third measurement occasion per day to further separate the measurement points.

Third, we limited ourselves to two types of job stressors, and within these types, we used a rather broad conceptualization of situational constraints. Future studies could assess other types of job stressors. With respect to situational constraints, a recent study (Liu, Nauta, Li, \& Fan, 2010) suggested differentiating between job context constraints, such as lack of equipment or supplies, and interpersonal constraints, such as interruptions by other people or inadequate help from others. It might be that the moderator effect can be found only for some types of constraints and not for others.

Fourth, we adopted a day-level approach. Although this approach adds an important perspective to research on work engagement and offers valuable insights, we do not know how our day-level findings generalize to other time frames. Therefore, future research should examine the dynamics between recovery level and work engagement within longer as well as shorter time frames. Longer time frames would imply week-level studies or longer term longitudinal designs, for instance, over several months. However, narrowing the time frame by using shorter assessment intervals might increase our understanding of the dynamics between work engagement and recovery. For instance, one might examine how episodes of high work engagement result in affective and energetic states during a work break and how work breaks, in turn, help one to become engaged when back at work again.

\section{Practical Implications and Conclusions}

Our study suggests practical implications that may help employees to be engaged at work. First, it is important that employees feel recovered when they come to work. Several avenues to a high recovery level should be considered, including beneficial recovery experiences at home, such as mental detachment from work and good sleep (Sonnentag et al., 2008). Managers should try not to interfere with these experiences, for instance, by respecting boundaries between employees' work and nonwork lives and by avoiding unfair treatment that has been shown to be associated with insomnia problems (Boswell \& Olson-Buchanon, 2007; Greenberg, 2006).

Furthermore, because situational constraints turned out to be a factor that reduced the benefits of a high recovery level on work engagement and of high work engagement on the subsequent recovery level, it is important to reduce situational constraints at work, for instance, by job design efforts (Semmer, 2006). However, as the reduction in situational constraints may not always be feasible (Holman, Axtell, Sprigg, Totterdell, \& Wall, 2010), it is important to prevent a dramatic drop in employees' recovery level on days when situation constraints occur, for example, by scheduling breaks that provide sufficient revitalization and by encouraging employees to actually take these breaks.

Taken together, our study shows that recovery level and work engagement are mutually related and probably reinforce each other. Importantly, this association becomes evident only during days without high levels of situational constraints, making reduction of and effective coping with this type of job stressor a crucial goal within stress management efforts.

\section{References}

Bakker, A. B., Albrecht, S., \& Leiter, M. P. (2011). Key questions regarding work engagement. European Journal of Work and Organizational Psychology, 20, 4-28. doi:10.1080/1359432X.2010.485352

Bakker, A. B., \& Bal, P. M. (2010). Weekly work engagement and performance: A study among starting teachers. Journal of Occupational and Organizational Psychology, 83, 189-206. doi:10.1348/ 096317909X402596

Bakker, A. B., \& Demerouti, E. (2007). The job demands-resources model: State of the art. Journal of Managerial Psychology, 22, 309-328. doi:10.1108/02683940710733115

Bakker, A. B., Schaufeli, W. B., Leiter, M. P., \& Taris, T. W. (2008). Work engagement: An emerging concept in occupational health psychology. Work \& Stress, 22, 187-200. doi:10.1080/02678370802393649

Bakker, A. B., van Emmerik, I. H., Geurts, S. A. E., \& Demerouti, E. (2008). Recovery turns job demands into challenges: A diary study on work engagement and performance. Working paper, Erasmus University Rotterdam, Rotterdam, the Netherlands.

Beal, D. J., Weiss, H. M., Barros, E., \& MacDermid, S. M. (2005). An episodic process model of affective influences on performance. Journal of Applied Psychology, 90, 1054-1068. doi:10.1037/00219010.90.6.1054

Binnewies, C., Sonnentag, S., \& Mojza, E. J. (2009). Daily performance at work: Feeling recovered in the morning as a predictor of day-level job performance. Journal of Organizational Behavior, 30, 67-93. doi: 10.1002/job.541

Bledow, R., Schmitt, A., Frese, M., \& Kühnel, J. (2011). The affective shift model of work engagement. Journal of Applied Psychology, 96, 12461257. doi: $10.1037 / \mathrm{a} 0024532$

Boswell, W. R., \& Olson-Buchanon, J. B. (2007). The use of communications technologies after hours: The role of work attitudes and worklife conflict. Journal of Management, 33, 592-610. doi:10.1177/ 0149206307302552

Crawford, E. R., LePine, J. A., \& Rich, B. L. (2010). Linking job demands and resources to employee engagement and burnout: A theoretical extension and meta-analytic test. Journal of Applied Psychology, 95, 834-848. doi:10.1037/a0019364

de Lange, A. H., Taris, T. W., Kompier, M. A. J., Houtman, I. L. D., \& Bongers, P. M. (2003). "The very best of the millennium": Longitudinal research and the demand-control-(support) model. Journal of Occupa tional Health Psychology, 8, 282-305. doi:10.1037/1076-8998.8.4.282

Demerouti, E., Bakker, A. B., Nachreiner, F., \& Schaufeli, W. B. (2001) Job demands-resources model of burnout. Journal of Applied Psychology, 86, 499-512. doi:10.1037/0021-9010.86.3.499

Demerouti, E., Bakker, A. B., Sonnentag, S., \& Fullagar, C. (2012). Work-related flow and energy at work and at home: A study on the role of daily recovery. Journal of Organizational Behavior, 33, 276-295. doi: $10.1002 /$ job.760

Gilboa, S., Shirom, A., Fried, Y., \& Cooper, C. (2008). A meta-analysis of work demand stressors and job performance: Examining main and moderating effects. Personnel Psychology, 61, 227-271. doi:10.1111/ j.1744-6570.2008.00113.x

Greenberg, J. (2006). Losing sleep over organizational injustice: Attenuating insomniac reactions to underpayment inequity with supervisory training in interactional justice. Journal of Applied Psychology, 91, 58-69. doi:10.1037/0021-9010.91.1.58

Greenhaus, J. H., \& Powell, G. N. (2006). When work and family are allies: A theory of work-family enrichment. Academy of Management Journal, 31, 72-92. doi:10.5465/AMR.2006.19379625

Hakanen, J. J., Perhoniemi, R., \& Toppinen-Tammer, S. (2008). Positive gain spirals at work: From job resources to work engagement, personal initiative and work-unit innovativeness. Journal of Vocational Behavior, 73, 78-91. doi:10.1016/j.jvb.2008.01.003

Halbesleben, J. R. B., Harvey, J., \& Bolino, M. C. (2009). Too engaged? 
A conservation of resources view of the relationship between work engagement and work interference with family. Journal of Applied Psychology, 94, 1452-1465. doi:10.1037/a0017595

Hockey, G. R. J. (1997). Compensatory control in the regulation of human performance under stress and high workload: A cognitive-energetical framework. Biological Psychology, 45, 73-93. doi:10.1016/S03010511(96)05223-4

Holman, D., Axtell, C. M., Sprigg, C. A., Totterdell, P., \& Wall, T. D. (2010). The mediating role of job characteristics in job redesign interventions: A serendipitous quasi-experiment. Journal of Organizational Behavior, 31, 84-105. doi:10.1002/job.631

Ilies, R., Dimotakis, N., \& De Pater, I. E. (2010). Psychological and physiological reactions to high workloads: Implications for well-being. Personnel Psychology, 63, 407-436. doi:10.1111/j.1744-6570.2010 .01175.x

Kühnel, J., Sonnentag, S., \& Bledow, R. (2012). Resources and time pressure as day-level antecedents of work engagement. Journal of $\mathrm{OC}$ cupational and Organizational Psychology, 85, 181-198. doi:10.111/ j.2044-8325.2011.02022.x

Leitner, K., \& Resch, M. G. (2005). Do the effects of job stressors on health persist over time? A longitudinal study with observational stressor measures. Journal of Occupational Health Psychology, 10, 18-30. doi: 10.1037/1076-8998.10.1.18

LePine, J. A., Podsakoff, N. P., \& LePine, M. A. (2005). A meta-analytic test of the challenge stressor-hindrance stressor framework: An explanation for inconsistent relationships among stressors and performance. Academy of Management Journal, 48, 764-775. doi:10.5465/ AMJ.2005.18803921

Liu, C., Nauta, M. M., Li, C., \& Fan, J. (2010). Comparisons of organizational constraints and their relations to strains in China and the United States. Journal of Occupational Health Psychology, 15, 452-467. doi: 10.1037/a0020721

Mauno, S., Kinnunen, U., \& Ruokolainen, M. (2007). Job demands and resources as antecedents of work engagement: A longitudinal study. Journal of Vocational Behavior, 70, 149-171. doi:10.1016/ j.jvb.2006.09.002

Newman, D. A., Joseph, D. L., \& Hulin, C. L. (2010). Job attitudes and employee engagement: Considering the attitude "A-factor." In S. Albrecht (Ed.), The handbook of employee engagement: Perspectives, issues, and research practice (pp. 43-61). Cheltenham, England: Elgar.

Peters, L. H., \& O'Connor, E. J. (1980). Situational constraints and work outcomes: The influences of a frequently overlooked construct. Academy of Management Review, 5, 391-397.

Peters, L. H., O’Connor, E. J., Eulberg, J. R., \& Watson, T. W. (1988). An examination of situational constraints in Air Force work settings. Human Performance, 1, 133-144. doi:10.1207/s15327043hup0102_4

Podsakoff, N. P., LePine, J. A., \& LePine, M. A. (2007). Differential challenge stressor-hindrance stressor relationships with job attitudes, turnover intention, turnover, and withdrawal behavior: A meta-analysis. Journal of Applied Psychology, 92, 438-454. doi:10.1037/00219010.92.2.438

Podsakoff, P. M., MacKenzie, S. B., Lee, J.-Y., \& Podsakoff, N. P. (2003). Common method biases in behavioral research: A critical review of the literature and recommended remedies. Journal of Applied Psychology, 88, 879-903. doi:10.1037/0021-9010.88.5.879

Preacher, K. J., Curran, P. J., \& Bauer, D. J. (2006). Computational tolls for probing interactions in multiple linear regression, multilevel modeling, and latent curve analysis. Journal of Educational and Behavioral Statistics, 31, 437-448. doi:10.3102/10769986031004437

Rodell, J. B., \& Judge, T. A. (2009). Can "good" stressors spark "bad" behaviors? The mediating role of emotions in links of challenge and hindrance stressors with citizenship and counterproductive behaviors. Journal of Applied Psychology, 94, 1438-1451. doi:10.1037/a0016752 Rothbard, N. P. (2001). Enriching or depleting? The dynamics of engage- ment in work and family roles. Administrative Science Quarterly, 46, 655-684. doi: $10.2307 / 3094827$

Ryan, R. M., \& Deci, E. L. (2000). Self-determination theory and the facilitation of intrinsic motivation, social development, and well-being. American Psychologist, 55, 68-78. doi:10.1037/0003-066X.55.1.68

Salanova, M., Agut, S., \& Peiró, J. M. (2005). Linking organizational resources and work engagement to employee performance and customer loyalty: The mediation of service climate. Journal of Applied Psychology, 90, 1217-1227. doi:10.1037/0021-9010.90.6.1217

Salanova, M., Llorens, S., \& Schaufeli, W. B. (2011). "Yes, I can, I feel good, and I just do it!" On gain cycles and spirals of efficacy beliefs, affect, and engagement. Applied Psychology, 60, 255-285. doi:10.1111/ j.1464-0597.2010.00435.x

Salanova, M., Schaufeli, W. B., Xanthopoulou, D., \& Bakker, A. B. (2010). The gain spiral of resources and work engagement: Sustaining a positive worklife. In A. B. Bakker \& M. P. Leiter (Eds.), Work engagement: Recent developments in theory and research (pp. 118-131). New York, NY: Psychology Press.

Sanz-Vergel, A. I., Demerouti, E., Moreno-Jiménez, B., \& Mayo, M. (2010). Work-family balance and energy: A day-level study on recovery conditions. Journal of Vocational Behavior, 76, 118-130. doi:10.1016/ j.jvb.2009.07.001

Schaufeli, W. B., \& Bakker, A. B. (2004). Job demands, job resources, and their relationship with burnout and engagement: A multi-sample study. Journal of Organizational Behavior, 25, 293-315. doi:10.1002/job.248

Schaufeli, W. B., Bakker, A. B., \& Salanova, M. (2006). The measurement of work engagement with a short questionnaire: A cross-national study. Educational and Psychological Measurement, 66, 701-716. doi: $10.1177 / 0013164405282471$

Schaufeli, W. B., Bakker, A. B., \& van Rhenen, W. (2009). How changes in job demands and resources predict burnout, work engagement and sickness absenteeism. Journal of Organizational Behavior, 30, 893-917. doi: 10.1002/job.595

Schaufeli, W. B., Salanova, M., Gonzáles-Romá, V., \& Bakker, A. B. (2002). The measurement of engagement and burnout: A two sample confirmatory factor analytic approach. Journal of Happiness Studies, 3, .71-92. doi:10.1023/A: 1015630930326

Schaufeli, W. B., Taris, T. W., \& van Rhenen, W. (2008). Workaholism, burnout, and work engagement: Three of a kind or three different kinds of employee well-being? Applied Psychology, 57, 173-203. doi: 10.1111/j.1464-0597.2007.00285.x

Semmer, N. (1984). Streßbezogene Tätigkeitsanalyse [Stress-oriented taskanalysis]. Weinheim, Germany: Beltz.

Semmer, N. K. (2006). Job stress interventions and the organization of work. Scandinavian Journal of Work Environment and Health, 32, 515-527. doi:10.5271/sjweh. 1056

Shirom, A. (2011). Vigor as a positive affect at work: Conceptualizing vigor, its relations with related constructs, and its antecedents and consequences. Review of General Psychology, 15, 50-64. doi:10.1037/ a0021853

Simbula, S. (2010). Daily fluctuations in teachers' well-being: A diary study using the job demands-resources model. Anxiety, Stress, \& Coping, 23, 563-584. doi:10.1080/10615801003728273

Sonnentag, S. (2003). Recovery, work engagement, and proactive behavior: A new look at the interface between non-work and work. Journal of Applied Psychology, 88, 518-528. doi:10.1037/0021-9010.88.3.518

Sonnentag, S., Binnewies, C., \& Mojza, E. J. (2008). "Did you have a nice evening?" A day-level study on recovery experiences, sleep, and affect. Journal of Applied Psychology, 93, 674-684. doi:10.1037/00219010.93.3.674

Sonnentag, S., Dormann, C., \& Demerouti, E. (2010). Not all days are created equal: The concept of state work engagement. In A. B. Bakker \& M. P. Leiter (Eds.), Work engagement: Recent developments in theory and research (pp. 25-38). New York, NY: Psychology Press. 
Sonnentag, S., \& Jelden, S. (2009). Job stressors and the pursuit of sport activities: A day-level perspective. Journal of Occupational Health Psychology, 14, 165-181. doi:10.1037/a0014953

Sonnentag, S., \& Kruel, U. (2006). Psychological detachment from work during off-job time: The role of job stressors, job involvement, and recovery-related self-efficacy. European Journal of Work and Organizational Psychology, 15, 197-217. doi:10.1080/13594320500513939

Spector, P. E. (2006). Method variance in organizational research: Truth or urban legend? Organizational Research Methods, 9, 221-232. doi: $10.1177 / 1094428105284955$

Spector, P. E., \& Jex, S. M. (1998). Development of four self-report measures of job stressors and strain: Interpersonal Conflict at Work Scale, Organizational Constraints Scale, Quantitative Workload Inventory, and Physical Symptoms Inventory. Journal of Occupational Health Psychology, 3, 356-367. doi:10.1037/1076-8998.3.4.356

Trougakos, J. P., \& Hideg, I. (2009). Momentary work recovery: The role of within-day work breaks. In S. Sonnentag, P. L. Perrewé, \& D. C. Ganster (Eds.), Current perspectives on job-stress recovery (pp. 37-84). Bingley, England: Emerald.

van Beek, I., Taris, T. W., \& Schaufeli, W. B. (2011). Workaholic and work engagement employees: Dead ringers or worlds apart? Journal of Occupational Health Psychology, 16, 468-482. doi:10.1037/a0024392

van Veldhoven, M. J. P. M., \& Sluiter, J. K. (2009). Work-related recovery opportunities: Testing scale properties and validity in relation to health. International Archives of Occupational and Environmental Health, 82, 1065-1075. doi:10.1007/s00420-009-0411-z

Watson, D., Clark, L. A., \& Tellegen, A. (1988). Development and validation of brief measures of positive and negative affect: The PANAS scales. Journal of Personality and Social Psychology, 54, 1063-1070. doi:10.1037/0022-3514.54.6.1063

Xanthopoulou, D., Bakker, A. B., Demerouti, E., \& Schaufeli, W. B. (2009a). Reciprocal relationships between job resources, personal resources, and work engagement. Journal of Vocational Behavior, 74, 235-244. doi:10.1016/j.jvb.2008.11.003

Xanthopoulou, D., Bakker, A. B., Demerouti, E., \& Schaufeli, W. B. (2009b). Work engagement and financial returns: A diary study on the role of job and personal resources. Journal of Occupational and Organizational Psychology, 82, 183-200. doi:10.1348/096317908X285633

Xanthopoulou, D., Bakker, A. B., Heuven, E., Demerouti, E., \& Schaufeli, W. B. (2008). Working in the sky: A diary study on work engagement among flight attendants. Journal of Occupational Health Psychology, 13, 345-356. doi:10.1037/1076-8998.13.4.345

Zapf, D. (1993). Stress-oriented analysis of computerized office work. European Work and Organizational Psychologist, 3, 85-100.

Zijlstra, F. R. H., \& Cropley, M. (2006). Recovery after work. In F. A. Jones, R. J. Burke, \& M. Westman (Eds.), Work-life balance: A psychological perspective (pp. 219-234). New York, NY: Psychology Press

Zohar, D., Tzischinski, O., \& Epstein, R. (2003). Effects of energy availability on immediate and delayed emotional reactions to work events. Journal of Applied Psychology, 88, 1082-1093. doi:10.1037/00219010.88.6.1082 